\title{
A new approach to multiblock copolymers using atom transfer radical coupling
}

\author{
René Nagelsdiek, Helmut Keul * , Hartwig Höcker
}

Lehrstuhl für Textilchemie und Makromolekulare Chemie der RWTH Aachen, Worringerweg 1, 52056 Aachen, Germany; Fax (+49) 241 - 80 22438;

keul@dwi.rwth-aachen.de

(Received: April 20, 2005; published: July 15, 2005)

\begin{abstract}
Atom transfer radical coupling (ATRC) is a method for chain extension of styrene homopolymers prepared by atom transfer radical polymerization (ATRP). This concept is used to produce multiblock copolymers from block copolymers prepared via ATRP of styrene using various macroinitiators. ATRC comprises the reactivation of the dormant species at the chain ends. In the absence of monomer, the active radical species recombine to give chain extension (from polystyrene, PS) or multiblock copolymers (from block copolymers). The application of ATRC to PSblock-poly(bisphenol A carbonate)-block-PS (PS-b-PC-b-PS) was not successful because chain degradation of the PC block occurs. However, poly(phenylene oxide)-block-PS (PPO- $b$-PS) and PS- $b$-PPO- $b$-PS were successfully transformed into tri- and multiblock copolymers by ATRC, although the coupling efficiency is not as high as observed for PS oligomers under similar conditions.
\end{abstract}

\section{Introduction}

Atom transfer radical coupling (ATRC) is a recent method used for coupling reactions of halide telechelic polystyrene prepared via ATRP [1-4]. The method was initially investigated by Fukuda et al. [1]. The technical term 'atom transfer radical coupling' was introduced by Yagci who was the first to realize the synthetic potential of ATRC for the preparation of $\alpha, \omega$-telechelic functional polystyrene [2]. Boutevin reported the successful ATRC of a poly(a-fluoroacrylate) [5]; moreover, the successful ATRC of a styrene-terminated poly(methyl acrylate) was reported by Matyjaszewski et al. [6]. ATRC is based on the application of $\mathrm{Cu}(0)$ to an ATRP system, leading to the reduction of any $\mathrm{Cu}(\mathrm{II})$ in the reaction medium to form $\mathrm{Cu}(\mathrm{I})$. The increase of $\mathrm{Cu}(\mathrm{I})$ in the reaction medium dramatically shifts the equilibrium between active and dormant species to the side of the active radical species (Scheme 1). A significant increase in radical concentration leads to the reaction between radical chain ends. In the case of $\mathrm{PS}$, the preferential reaction is the radical coupling reaction, the rate of which is estimated to increase by about three orders of magnitude if compared to the reaction conditions of ATRP [1]. Up to now, ATRC has been used for the preparation of $\alpha, \omega-$ telechelic functional polymers by coupling of an $\alpha$-functional polystyrene prepared by ATRP; in these cases dimerization occurs. Furthermore, the application of ATRC to PS prepared with bifunctional ATRP initiators leads to a significant increase in molecular weight and a multimodal molecular weight distribution due to the formation of a mixture of dimers, trimers etc. [1]. Although from the mechanistic point of view, $\mathrm{Cu}(\mathrm{I})$ 
species are a prerequisite for the reactivation of the dormant species, some authors $[3,5]$ use halide telechelic polymers and $\mathrm{Cu}(0)$ in the presence of a ligand without addition of a $\mathrm{Cu}(\mathrm{I})$ species. In these cases, in situ formation of oxidized $\mathrm{Cu}$ species must be assumed.

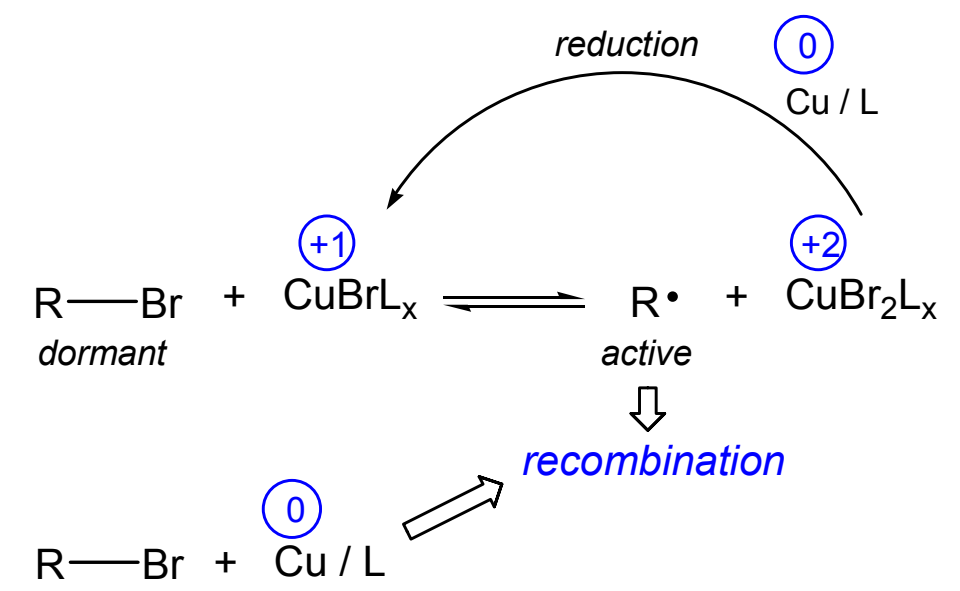

Scheme 1. Principle of the atom transfer radical coupling (ATRC) of polymer chains prepared by ATRP $(\mathrm{L}=$ ligand $)$
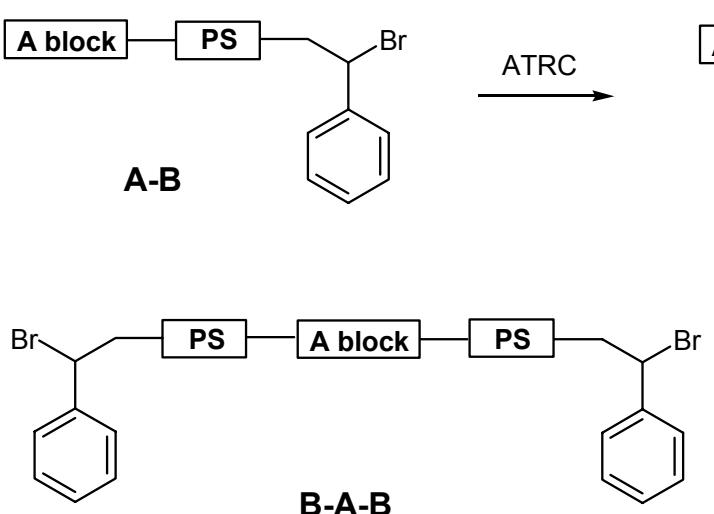

B-A-B

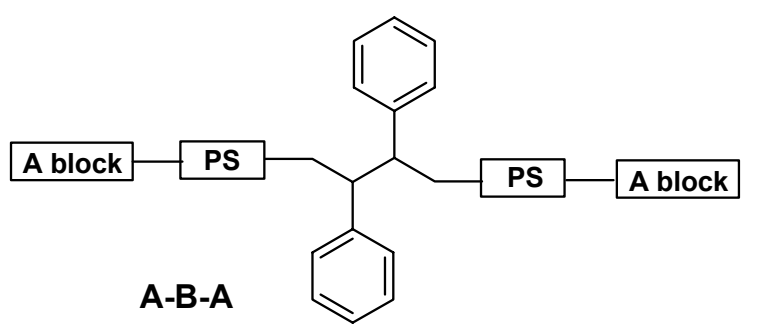

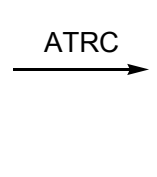$$
\text { ( }
$$

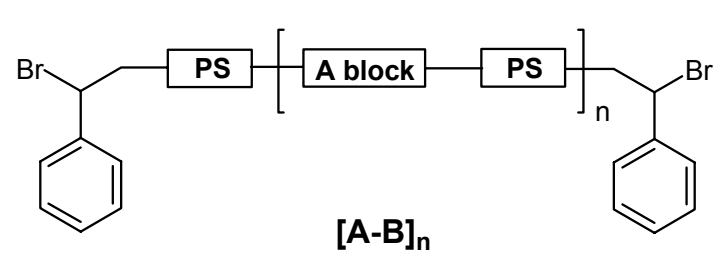

$[\mathrm{A}-\mathrm{B}]_{\mathrm{n}}$

Scheme 2. General principle of the ATRC of diblock and triblock copolymers (shown here for block copolymers containing 'A block' segments and PS segments with dormant PS end groups)

The application of ATRC to block copolymers prepared by ATRP should in general offer a new approach to chain extension and to the preparation of multiblock copolymers. This is of particular interest because ATRP not only allows the formation of block copolymers by sequential addition of vinyl monomers, but gives also access to block copolymers, the segments of which polymerize according to different mechanisms; this is achieved by the application of suitable macroinitiators prepared by polycondensation (high temperature thermoplastic polymers like polycarbonate and poly(phenylene oxide)). The use of these macroinitiators (A block) in the ATRP of vinyl monomers $(B)$ gives access to A-B diblock copolymers (in the case of a monofunctional macroinitiator) or B-A-B triblock copolymers (in the case of a bifunctional 
macroinitiator). Upon coupling reactions of these readily available ATRP products (A-B or B-A-B), A-b-A structures or multiblock copolymers ([A-B $]_{n}$ structures) would also be available (Scheme 2).

To the best of our knowledge, the atom transfer radical coupling of block copolymers has not yet been reported, since recent reports discuss only the ATRC of homopolymers, especially of oligomers. Therefore, we considered it to be reasonable to study the ATRC of block copolymers containing PS segments and segments consisting of a high- $T_{\mathrm{g}}$ polymer. In a previous paper, the preparation of PS-block-poly(bisphenol A carbonate)-block-PS (PS-b-PC-b-PS) via ATRP using polycarbonate macroinitiators was described [7]. Moreover, we reported on the successful synthesis of mono- and bifunctional ATRP macroinitiators based on poly(2,6-dimethyl-1,4-phenylene oxide) (PPO) [8]. In this communication, we report on the results obtained for the ATRC of these block copolymers with catalyst systems $\mathrm{Cu}(0) / \mathrm{CuBr} /$ ligand and $\mathrm{Cu}(0) /$ ligand.

\section{Results and discussion}

We started our investigation with ATRC of bromotelechelic PS using the catalyst systems $\mathrm{Cu}(0) / \mathrm{CuBr} /$ ligand and $\mathrm{Cu}(0) /$ ligand. PS was prepared by ATRP of styrene in solution ( $m$-xylene) using a bifunctional initiator ( $\alpha, \alpha^{\prime}$-dibromo- $p$-xylene); in order to keep the end group functionality high, we polymerized up to a conversion of $77 \%$.

Based on ref. [3], the subsequent coupling reaction was carried out in anisole at $90^{\circ} \mathrm{C}$ for $15 \mathrm{~h}$ (Tab. 1, entry 1, cf. Exptl. part) using a stoichiometric amount of $\mathrm{Cu}(0)$ and the ligand pentamethyldiethylenetriamine (PMDETA), but without the addition of $\mathrm{CuBr}$ (i.e., mole ratio PS:Cu:PMDETA $=1: 2: 2$, based on $M_{n, G P C}$ ). An increase in molecular weight and a multimodal molecular weight distribution were observed. The increase of $M_{\mathrm{n}}$ was by about a factor of two (reactant: $M_{\mathrm{n}}=4100, M_{\mathrm{w}} / M_{\mathrm{n}}=1.13$; product: $M_{\mathrm{n}}=$ $\left.8300, M_{\mathrm{w}} / M_{\mathrm{n}}=1.98\right)$, but a peak deconvolution of the product GPC curve reveals major amounts of dimer, trimer, and higher coupling products (Fig. 1). However, still a significant amount of non-converted starting polymer is present.

In a second procedure (based on ref. [2]), the reaction was carried out in toluene at $110^{\circ} \mathrm{C}$ with $\mathrm{Cu}(0)$ in the presence of $\mathrm{CuBr}$ and ligand (mole ratio $\mathrm{PS}: \mathrm{Cu}: \mathrm{CuBr}$ : PMDETA $=1: 10: 2: 14.4$ ) and a reaction time of 90 min (Tab. 1, entry 2). However, the product obtained is very similar to that of the previous procedure (product: $M_{\mathrm{n}}=$ $\left.8900, M_{w} / M_{n}=1.96\right)$. Hence, the addition of $\mathrm{CuBr}$ does not improve the coupling efficiency significantly.

Therefore, another reason for the moderate increase of the molecular weight has to be found; this might be the end group functionality of the telechelic PS used. To increase the end group functionality, ATRP of styrene using the bifunctional initiator dimethyl 2,6-dibromoheptanedioate (DMDBHD) was carried out in bulk to a conversion of only $29 \%$. The PS obtained reveals a high molecular weight shoulder, which was attributed to a recombination taking place already during the polymerization (due to the higher concentration of active species in bulk than in solution). However, this is not of importance for our purpose since the small amount of dimer formed during the polymerization is also a valid reactant for the intended coupling reaction.

The ATRC of the bifunctional PS was then carried out in toluene at $110^{\circ} \mathrm{C}$ both in the presence and in the absence of $\mathrm{CuBr}$; $\mathrm{Me}_{6} \mathrm{TREN}$ (tris(dimethylaminoethyl)amine) was used as the ligand (Tab. 1, entries 3 and 4). This time, the increase in $M_{\mathrm{n}}$ and $M_{\mathrm{w}}$ was significantly more pronounced (reactant: $M_{\mathrm{n}}=5100, M_{\mathrm{w}}=6200$; product in 
the presence of $\mathrm{CuBr}: M_{\mathrm{n}}=23900, M_{\mathrm{w}}=178700$; product in the absence of $\mathrm{CuBr}$ : $M_{\mathrm{n}}=25900, M_{\mathrm{w}}=161700$; cf. Fig. 2). The presence of $\mathrm{CuBr}$ has no effect on the result of the coupling, but it is obvious that the coupling reaction is more effective than in the examples discussed before.

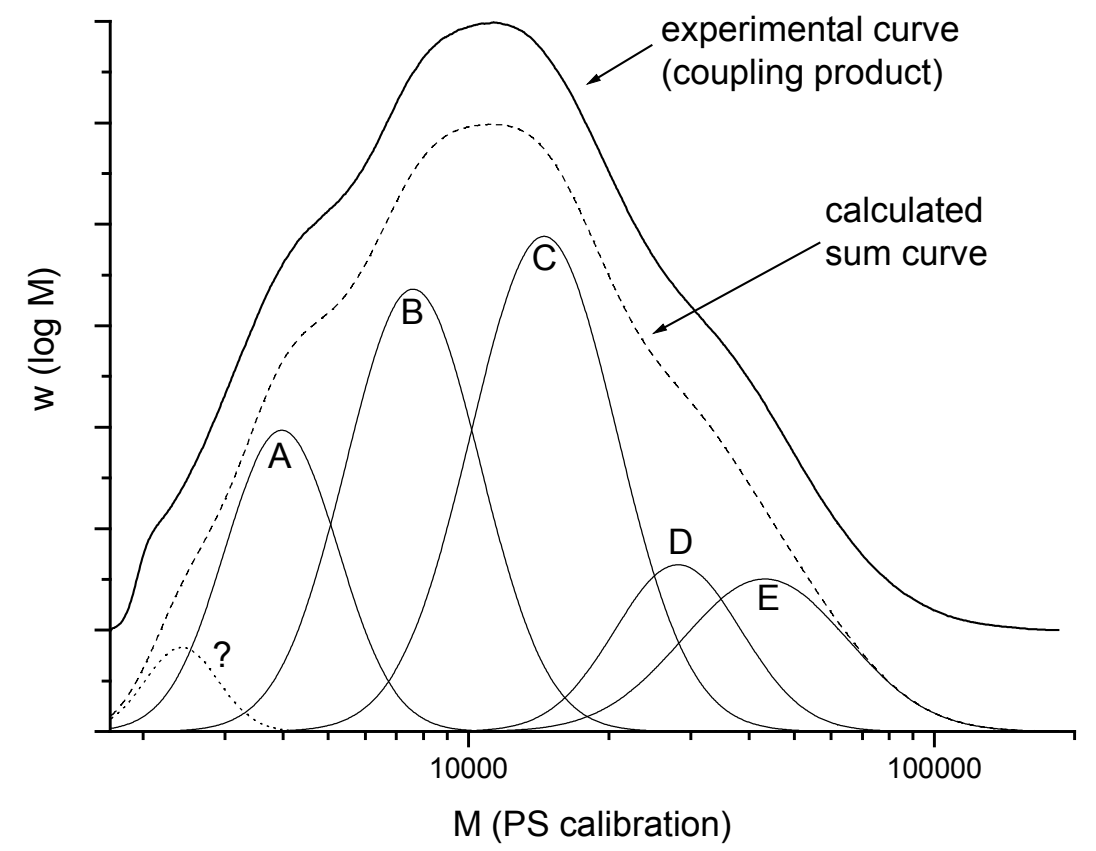

Fig. 1. Peak fitting to a gel permeation chromatography (GPC) plot of the ATRC product obtained from bis-Br-telechelic PS (reactant polymer prepared in solution, $M_{\mathrm{n}}$ $\left.=4100, M_{\mathrm{w}} / M_{\mathrm{n}}=1.13\right)$. Curves $\mathrm{A}-\mathrm{E}$ are the calculated curves of reactant (A), dimer (B), trimer (C), etc. The calculated values for $M_{\mathrm{n}}, M_{\mathrm{w}} / M_{\mathrm{n}}$ and the fraction of the total peak area are: "?" (not assigned, 2400, 1.03, 2.7\%), A (3800, 1.08, 15.6\%), B (7200, $1.12,27.3 \%)$, C $(13200,1.14,33.1 \%)$, D $(26800,1.10,9.7 \%)$, E (39800, 1.18, $11.6 \%)$

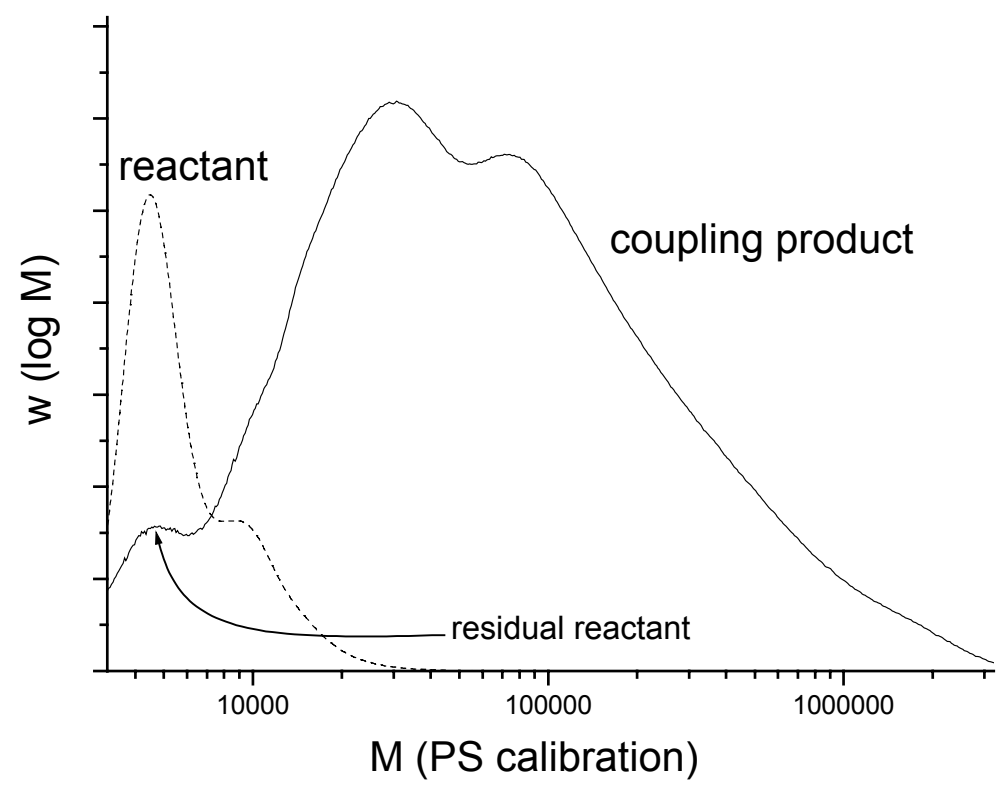

Fig. 2. GPC curves of bis-Br-telechelic PS (prepared in bulk, $M_{\mathrm{n}}=5100, M_{\mathrm{w}}=6200$ ) and of the product obtained after ATRC $\left(M_{\mathrm{n}}=25900, M_{\mathrm{w}}=161700\right)$ 
Based on these results, we studied the ATRC of PS- $b$-PC- $b$-PS. The application of ATRC to block copolymers is expected to have two major drawbacks: (i) Block copolymers are expected to have a higher molecular weight than the low molecular weight homopolymers used up to now; thus the concentration of halide end groups involved in the coupling reaction is low. (ii) An interaction of radicals with the polycondensate used as A block might disturb the reaction.

PS- $b$-PC-b-PS was prepared by ATRP of styrene using a bifunctional PC macroinitiator [7]. Instead of an increase of $M_{\mathrm{n}}$, a decrease was observed (Tab. 2, entries 1 and 2). A closer look at the shape of the GPC eluograms revealed that the molecular weight distribution becomes multimodal (Fig. 3a). These results are explained by a degradation of the PC segments. As a control experiment, we treated $\mathrm{OH}$-telechelic bisphenol A polycarbonate under the conditions of ATRC. Corresponding to the aforementioned results, GPC analysis of the product obtained indicated chain degradation (Fig. 3b). Therefore it is concluded that block copolymers with PC segments are not suitable for coupling reactions involving ATRC conditions.

a)

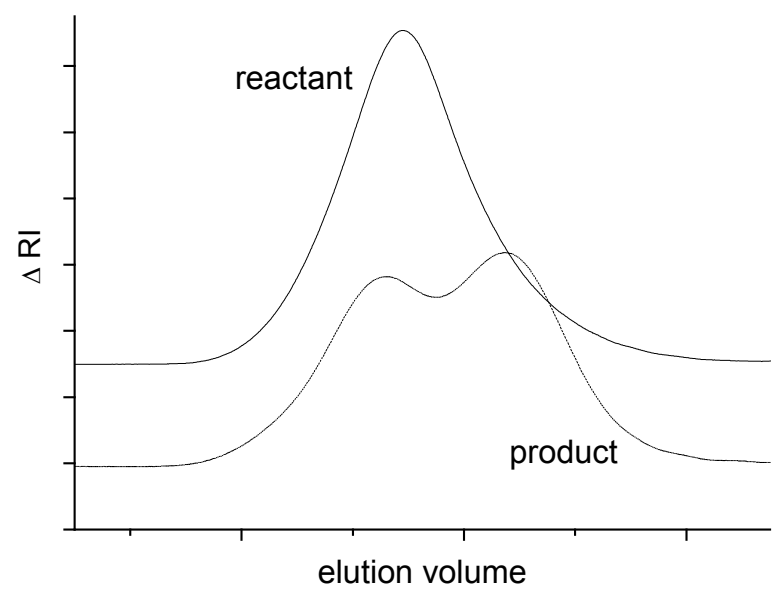

b)

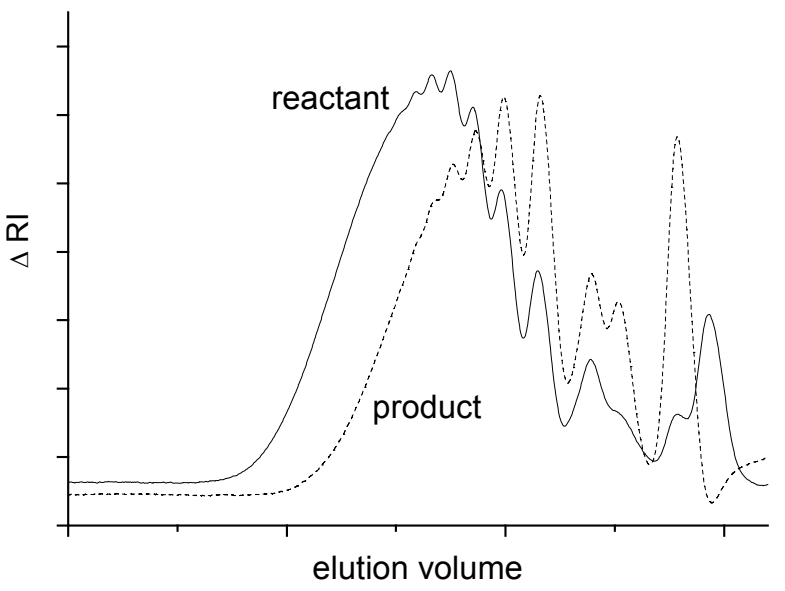

Fig. 3. GPC eluograms of the ATRC product of (a) PS- $b$-PC- $b$-PS (solid line: reactant, $M_{\mathrm{n}}=9400, M_{\mathrm{w}} / M_{\mathrm{n}}=1.24$; dotted line: product, $M_{\mathrm{n}}=7400, M_{\mathrm{w}} / M_{\mathrm{n}}=1.36$; cf. Tab. 2, entry 2) and (b) HO-(PC)-OH (solid line: reactant, $M_{\mathrm{n}}=4800, M_{\mathrm{w}} / M_{\mathrm{n}}=1.24$; dotted line: product, $M_{\mathrm{n}}=3700, M_{\mathrm{w}} / M_{\mathrm{n}}=1.15$; cf. Tab. 2, entry 3)

In contrast to polycarbonate, poly(phenylene oxide) (PPO) is stable under ATRC conditions $\left(\mathrm{Cu}(0) / \mathrm{PMDETA}, 110^{\circ} \mathrm{C}\right.$ in $m$-xylene, $\left.22 \mathrm{~h}\right)$ since no change in molecular weight was observed (Tab. 3, entry 7). Encouraged by these results, ATRC was applied to PS/PPO di- and triblock copolymers; the synthesis of these block copolymers was carried out according to ref. [8]. The results (Tab. 3) clearly reveal that the coupling reactions of bifunctional polymers are much more efficient than the one of the monofunctional polymer. Depending on the degree of polymerization of the starting material and the reaction conditions, $M_{\mathrm{w}}$ of the product is higher by a factor of 2 - 11. This clearly indicates that a radical coupling process takes place.

However, not only a coupling reaction between two radical chain ends appears to be possible. With respect to our investigation of the ATRP of styrene using PPO macroinitiators [8], a coupling reaction between the active PS radical chain end and the repeating unit of the macroinitiator segments might also contribute to the molecular weight increase. The coupling induced by PPO repeating units is explained by a 
hydrogen transfer from the $\mathrm{CH}_{3}$ groups of the PPO repeating units to an active chain end, followed by recombination reactions.

In the case of the diblock copolymer (Tab. 3, entry 1), peak deconvolution (Fig. 4) of the GPC plot reveals the superposition of the starting material (measured for the starting material: $M_{\mathrm{n}}=9000$; calculated by peak fitting: $M_{\mathrm{n}}=8800$ ) and a higher molecular weight polymer (calculated $M_{n}=32300$; calculated peak ratio of low to high molecular weight product: 1.7:1). $M_{\mathrm{n}}$ of the product is not exactly doubled because of the different hydrodynamic behaviour of PS- $b$-PPO and PPO- $b$-PS- $b-$ PPO. The fact that - in contrast to the ATRC of PS - part of the reactant diblock copolymer is not involved in the coupling process is explained in the following way: (i) A competing reaction - disproportionation - does not lead to an increase in molecular weight. (ii) The end group functionalization of the diblock copolymer (i.e., bromine end groups) is not quantitative. (iii) Hydrogen transfer from the $\mathrm{CH}_{3}$ groups of the PPO repeating units to active chain ends leads to irreversible termination. By using triblock copolymers in the radical coupling process, these undesired effects are minimized (at least one chain end will stay active).

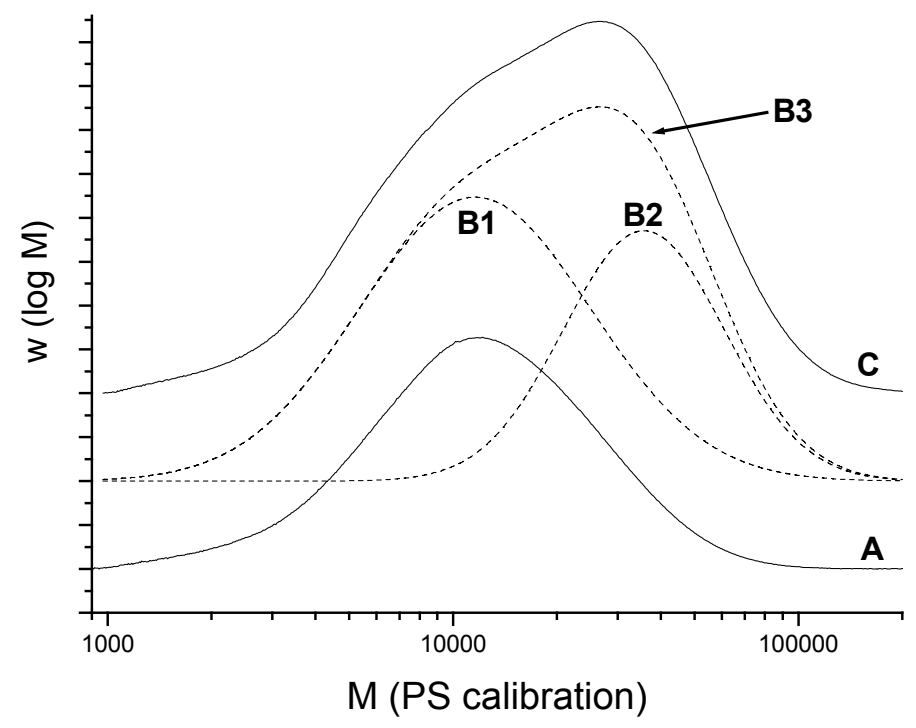

Fig. 4. Peak fitting to GPC plots of the ATRC product obtained from PS- $b$-PPO (Tab. 3 , entry 1). Solid curves: measured GPC curves of the diblock copolymer $\left(\mathrm{A}, M_{\mathrm{n}}=\right.$ $\left.9000, M_{\mathrm{w}}=16200\right)$ and the product of treatment under ATRC conditions $\left(\mathrm{C}, M_{\mathrm{n}}=\right.$ 11900, $M_{\mathrm{w}}=26100$ ); dashed curves: calc. values for fractions (B1, $M_{\mathrm{n}}=8800, M_{\mathrm{w}}=$ $\left.16400 ; \mathrm{B} 2, M_{\mathrm{n}}=32300, M_{\mathrm{w}}=42900\right)$ and sum curve $\left(\mathrm{B} 3, M_{\mathrm{n}}=12100, M_{\mathrm{w}}=26200\right)$

The highest increase in molecular weight is observed for entry 6 , Tab. 3 . In this experiment, the reactant triblock copolymer has a comparatively low molecular weight and the optimized conditions for the ATRP of PS homopolymer (reactant polymer prepared by bulk ATRP, Me ${ }_{6}$ TREN instead of PMDETA as the ligand) were chosen. The observation also corresponds to the investigations of Fukuda et al. [1], in which a higher extent of coupling reaction was found for shorter chains and explained by the chain length dependence of the termination rate constant $\left(k_{t}\right.$ is larger for shorter chains).

In contrast to the ATRC of PS homopolymers, an influence of $\mathrm{CuBr}$ addition to the reaction mixture is found for the ATRC of the block copolymers. $M_{w}$ of the product 
obtained under identical reaction conditions is commonly higher in the presence of $\mathrm{CuBr}$ ( Tab. 3, entries 3A/3B and 4A/4B). In entry $5 \mathrm{~A} / 5 \mathrm{~B}$, the measured $M_{\mathrm{w}}$ is lower if $\mathrm{CuBr}$ is added, but the product obtained after $24 \mathrm{~h}$ is partially insoluble, indicating the formation of a polymer network; this crosslinking process is ascribed to coupling reactions involving the PPO repeating units (hydrogen transfer, vide supra). Since the polymer molecules involved in this crosslinking process (and thus polymers with high molecular weight) are not accessible to the analysis by means of GPC, the soluble fraction consists of lower molecular weight polymer, therefore having a lower $M_{\mathrm{w}}$ than in the corresponding reaction in the absence of $\mathrm{CuBr}$. The higher amount of coupling when adding $\mathrm{CuBr}$ to the reaction mixture was ascribed to a faster establishment of the ATRC equilibrium. If a $\mathrm{Cu}(\mathrm{I})$ species is present right from the beginning of the reaction, a high concentration of active radical species is rapidly formed; this process increases the probability of a recombination reaction. In contrast, if $\mathrm{CuBr}$ is not present in the beginning of the reaction, the $\mathrm{Cu}(\mathrm{I})$ species is assumed to be formed in situ, i.e., the concentration of radical species is low in the initial phase of the reaction. Undesired side reactions of the radicals become more significant because the probability of the desired recombination is reduced. In the ATRC of PS oligomers, this effect is not of importance because the concentration of halide end groups is in general higher than in the case of the PS/PPO block copolymers and, moreover, the hydrogen transfer side reaction of the PPO repeating units is excluded.

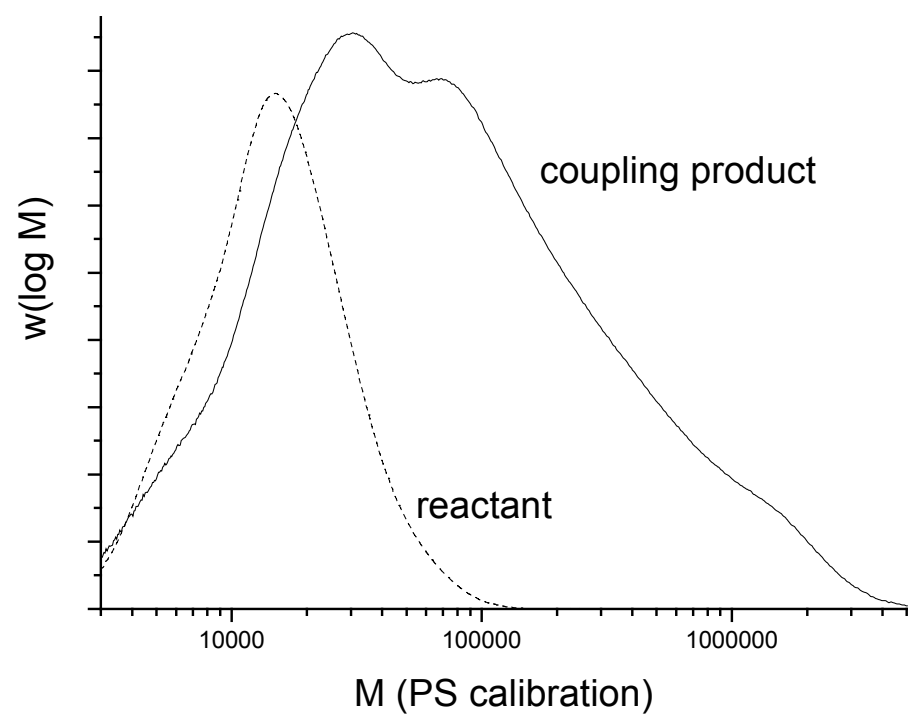

Fig. 5. GPC curves of PS- $b$-PPO-b-PS (reactant, $M_{\mathrm{n}}=11300, M_{\mathrm{w}}=18100$ ) and of the product obtained after ATRC $\left(M_{\mathrm{n}}=26400, M_{\mathrm{w}}=199500\right.$; cf. Tab. 3, entry 6)

\section{Conclusion}

The results presented in the literature and those obtained in this paper permit the conclusion that the prerequisites of an ATRC are given for PS and other telechelics with a dormant styrene ATRP end group. The coupling efficiency for block copolymers with PS and PPO segments is lower than in the case of low molecular weight PS homopolymers because of the smaller concentration of reactive end groups compared to the concentration of repeating units and because of side reactions involving the PPO repeating units; however, in the case of bifunctional PS- $b-\mathrm{PPO}-b-$ PS block copolymers, a clear increase in molecular weight was achieved. 


\section{Experimental part}

\section{Materials}

Styrene $\left(99 \%\right.$, Aldrich) was purified via column chromatography over $\mathrm{Al}_{2} \mathrm{O}_{3}$ (Fluka, type 5016A basic). Copper powder (99.5\%, 150 mesh, Aldrich), $\mathrm{CuBr}$ (98\%, Aldrich), pentamethyldiethylenetriamine (PMDETA, > 98\%, Merck), $\alpha, \alpha$ '-dibromo- $p$-xylene (DBX, 97\%, Aldrich), dimethyl 2,6-dibromoheptanedioate (DMDBHD, 97\%, Aldrich), toluene (> 99.5\%, Riedel-de Haen), $m$-xylene (99\%, Aldrich), and anisole (99\%, Aldrich) were used without further purification. Tris(dimethylaminoethyl)amine (Me $\left.\mathrm{M}_{6} \mathrm{TREN}\right)$ was prepared according to ref. [9]. Br-telechelic PS was prepared via ATRP according to the literature and to the experience of our group $[4,10]$.

All reactions were carried out in nitrogen atmosphere. Nitrogen (Linde, 5.0) was passed over molecular sieves $(4 \AA)$ and finely distributed potassium on aluminium oxide.

\section{Measurements}

${ }^{1} \mathrm{H}$ NMR spectra were recorded on a Bruker DPX-300 FT-NMR spectrometer at 300 $\mathrm{MHz}$. Deuterated chloroform $\left(\mathrm{CDCl}_{3}\right)$ was used as a solvent, and tetramethylsilane (TMS) served as the internal standard.

All molecular weight values $\left(M_{\mathrm{n}}\right.$ and $\left.M_{\mathrm{w}}\right)$ were estimated by gel permeation chromatography (GPC) using PS calibration. GPC analyses were carried out in tetrahydrofuran (THF) for PS homopolymers and PS/PPO block copolymers. In the case of PC homopolymer and PS- $b$-PC- $b$-PS, $N, N$-dimethylacetamide (DMAc) was used as the eluent. GPC measurement of the PPO homopolymer sample was performed in chloroform.

GPC analyses performed with THF as the eluent were carried out using a high pressure liquid chromatography pump (PL-LC 1120 HPLC) and a refractive index detector (ERC-7515A) at $35^{\circ} \mathrm{C}$. The eluting solvent was THF with $250 \mathrm{mg} / \mathrm{L} \mathrm{2,6-di-}$ tert-butyl-4-methylphenol (Aldrich) and a flow rate of $1.0 \mathrm{~mL} / \mathrm{min}$. Four columns with MZ-DVB gel were applied: length of each column $300 \mathrm{~mm}$, diameter $8 \mathrm{~mm}$, diameter of the gel particles $5 \mu \mathrm{m}$, nominal pore widths $50,100,1000,10000 \AA$.

GPC analyses using DMAc as the eluting solvent were carried out using a hightemperature GPC device at $80^{\circ} \mathrm{C}$ (Polymer Laboratories PL-GPC210 with a Bischoff HPLC contact pump) and a refractive index detector (Polymer Laboratories). The eluting solvent was used with $2.44 \mathrm{~g} / \mathrm{L} \mathrm{LiCl}$ and a flow rate of $0.8 \mathrm{~mL} / \mathrm{min}$. Four columns with MZ-DVB gel were applied: length of each column $300 \mathrm{~mm}$, diameter 8 $\mathrm{mm}$, diameter of gel particles $5 \mu \mathrm{m}$, nominal pore width 100, 100, 1000, $10000 \AA$. Chloroform GPC was performed at room temperature using a HPLC pump (PL-LC $1120 \mathrm{HPLC}$ ) and a refractive index detector (ERC-7515A). The eluting solvent was chloroform (HPLC grade, Fisher Scientific) with a flow rate of $0.8 \mathrm{~mL} / \mathrm{min}$. Four columns with MZ-Gel SDPlus were applied: Length of each column $300 \mathrm{~mm}$, diameter $8 \mathrm{~mm}$, diameter of gel particles $5 \mu \mathrm{m}$, nominal pore widths $50,100,1000$, $10000 \AA$.

For all GPC devices, calibration was achieved using polystyrene standards. For peak deconvolution, a peak fitting software (hs NTeqGPC V 6.2.12, Hard- und Software $\mathrm{mbH}$, Dr. W. Schupp) was used. 


\section{ATRC of Br-telechelic PS}

In a typical procedure, bis-Br-telechelic PS $\left(0.50 \mathrm{~g} ; M_{\mathrm{n}}=5100, M_{\mathrm{w}}=6200\right), \mathrm{Cu}(0)$ powder (0.21 g, $3.3 \mathrm{mmol}), \mathrm{CuBr}(0.09 \mathrm{~g}, 0.7 \mathrm{mmol}), \mathrm{Me}_{6} \operatorname{TREN}(0.22 \mathrm{~g}, 1.3 \mathrm{mmol})$, and toluene $(1.5 \mathrm{~mL})$ were stirred at $110^{\circ} \mathrm{C}$ for $24 \mathrm{~h}$. The mixture was cooled to room temperature, quenched with $\mathrm{CH}_{2} \mathrm{Cl}_{2}$, stirred with $\mathrm{Al}_{2} \mathrm{O}_{3}$, filtered, and precipitated into methanol (yield: $0.28 \mathrm{~g}, 56 \% ; M_{\mathrm{n}}=23900, M_{\mathrm{w}}=178700$ ).

Tab. 1. ATRC of Br-telechelic PS under various conditions (reactions carried out in toluene at $110^{\circ} \mathrm{C}$; GPC analyses performed in THF as the eluting solvent)

\begin{tabular}{|c|c|c|c|c|c|c|c|c|c|c|c|}
\hline \multirow[t]{2}{*}{ No. } & \multicolumn{2}{|c|}{ Reactant } & \multicolumn{2}{|c|}{ Product } & \multirow{2}{*}{$\begin{array}{l}\text { React. } \\
\text { in } \mathrm{g}\end{array}$} & \multirow{2}{*}{$\begin{array}{c}\mathrm{Cu}(0) \\
\text { in } \mathrm{g} \text { (in } \\
\mathrm{mmol})\end{array}$} & \multirow{2}{*}{$\begin{array}{c}\mathrm{CuBr} \\
\text { in } \mathrm{g} \text { (in } \\
\mathrm{mmol} \text { ) }\end{array}$} & \multirow{2}{*}{$\begin{array}{l}\text { Ligand } \\
\text { in } \mathrm{g} \text { (in } \\
\mathrm{mmol} \text { ) }\end{array}$} & \multirow{2}{*}{$\begin{array}{l}\text { Toluene } \\
\text { in } \mathrm{mL}\end{array}$} & \multirow{2}{*}{$\stackrel{t}{t}$ in $\mathrm{h}$} & \multirow[t]{2}{*}{$q^{\text {a) }}$} \\
\hline & $M_{\mathrm{n}, \mathrm{GPC}}$ & $M_{\mathrm{w}, \mathrm{GPC}}$ & $M_{\mathrm{n}, \mathrm{GPC}}$ & $M_{\mathrm{w}, \mathrm{GPC}}$ & & & & & & & \\
\hline $1^{\text {b) }}$ & 4100 & 4600 & 8300 & 16400 & 1.00 & $\begin{array}{l}0.03 \\
(0.5)\end{array}$ & -- & $\begin{array}{l}\text { PMDETA } \\
0.08(0.5)\end{array}$ & $4^{\text {d) }}$ & 15 & 0.51 \\
\hline $2^{b)}$ & 4100 & 4600 & 8900 & 17400 & 1.00 & $\begin{array}{l}0.15 \\
(2.3)\end{array}$ & $\begin{array}{l}0.07 \\
(0.5)\end{array}$ & $\begin{array}{l}\text { PMDETA } \\
0.58(3.4)\end{array}$ & 5 & 1.5 & 0.54 \\
\hline $3^{c)}$ & 5100 & 6200 & 23900 & 178700 & 0.50 & $\begin{array}{l}0.21 \\
(3.3)\end{array}$ & $\begin{array}{l}0.09 \\
(0.7)\end{array}$ & $\begin{array}{c}\mathrm{Me}_{6} \text { TREN } \\
0.22(1.3)\end{array}$ & 1.5 & 24 & 0.79 \\
\hline $4^{c)}$ & 5100 & 6200 & 25900 & 161700 & 0.50 & $\begin{array}{l}0.21 \\
(3.3)\end{array}$ & -- & $\begin{array}{c}\mathrm{Me}_{6} \text { TREN } \\
0.22(1.3)\end{array}$ & 1.5 & 24 & 0.80 \\
\hline
\end{tabular}

a) The extent of the coupling reaction $q$ is given by the equation: $q=1-M_{n, \text { reactant }} / M_{n, \text { product }}{ }^{\text {b) }} \mathrm{PS}$ prepared by solution ATRP in $m$-xylene (conversion: $77 \%$ ). ${ }^{\text {c) }}$ PS prepared by bulk ATRP (conversion: $29 \%$ ). ${ }^{\text {d) }}$ ATRC carried out in anisole at $90^{\circ} \mathrm{C}$.

Preparation of PS-b-PC-b-PS, PPO-b-PS, and PS-b-PPO-b-PS

PS- $b$-PC- $b$-PS was prepared by ATRP of styrene using bifunctional PC macroinitiators according to ref. [7]; these initiators were prepared by means of esterification of hydroxy telechelic PC with 2-bromoisobutyryl bromide.

PPO- $b$-PS and PS- $b$-PPO- $b$-PS were prepared by ATRP of styrene using mono- or bifunctional PPO macroinitiators according to ref. [8]; analogously, these initiators were prepared by means of esterification of mono- and bishydroxy-telechelic PPO with 2-bromoisobutyryl bromide.

\section{Atom transfer radical coupling of $P S-b-P C-b-P S$}

Dibromotelechelic PS- $b$-PC- $b-P S\left(1.00 \mathrm{~g} ; M_{\mathrm{n}}=9400, M_{\mathrm{w}}=11700\right), \mathrm{Cu}(0)$ powder $(0.11 \mathrm{~g}, 1.8 \mathrm{mmol})$, PMDETA $(0.37 \mathrm{~g}, 2.1 \mathrm{mmol})$, and anisole $(5 \mathrm{~mL})$ were stirred at $110^{\circ} \mathrm{C}$ for $18 \mathrm{~h}$. The mixture was cooled to room temperature, quenched with $\mathrm{CH}_{2} \mathrm{Cl}_{2}$ and precipitated into methanol (yield: $0.47 \mathrm{~g}, 47 \% ; M_{\mathrm{n}}=7400, M_{\mathrm{w}}=10100$ ).

\section{Atom transfer radical coupling of PS/PPO block copolymers}

Typical procedure: Dibromotelechelic PS- $b$-PPO- $b$-PS $\left(0.30 \mathrm{~g} ; M_{\mathrm{n}}=11300, M_{\mathrm{w}}=\right.$ $18100), \mathrm{Cu}(0)$ powder $(0.03 \mathrm{~g}, 0.4 \mathrm{mmol}), \mathrm{CuBr}(0.01 \mathrm{~g}, 0.1 \mathrm{mmol}), \mathrm{Me}_{6} \operatorname{TREN}(0.05$ $\mathrm{g}, 0.2 \mathrm{mmol})$, and toluene $(2 \mathrm{~mL})$ were stirred at $110^{\circ} \mathrm{C}$ for $24 \mathrm{~h}$. The mixture was cooled to room temperature, quenched with toluene and precipitated into methanol (yield: $0.22 \mathrm{~g}, 72 \% ; M_{\mathrm{n}}=26400, M_{\mathrm{w}}=199500$ ). 
Tab. 2. Results of the treatment of PS- $b-P C-b-P S$ and of hydroxy-telechelic $P C$ under ATRC conditions (all reactions carried out in anisole at $110^{\circ} \mathrm{C}$ for $18 \mathrm{~h}$; GPC analyses performed in DMAc as the eluting solvent)

\begin{tabular}{|c|c|c|c|c|c|c|c|c|c|c|}
\hline No. & $\begin{array}{l}\text { Reactant } \\
\text { type }\end{array}$ & $\begin{array}{r}\text { Rea } \\
M_{\mathrm{n}, \mathrm{GPC}}\end{array}$ & $\begin{array}{l}\text { ctant } \\
M_{\mathrm{w}, \mathrm{GPC}}\end{array}$ & $\begin{array}{r}\text { Pro } \\
M_{\mathrm{n}, \mathrm{GPC}}\end{array}$ & $\begin{array}{l}\text { duct } \\
M_{\mathrm{w}, \mathrm{GPC}}\end{array}$ & $\begin{array}{l}\text { Reactant } \\
\text { in } \mathrm{g}\end{array}$ & $\begin{array}{l}\mathrm{Cu}(0) \\
\text { in } \mathrm{g}(\text { in } \\
\mathrm{mmol})\end{array}$ & $\begin{array}{l}\text { PMDETA } \\
\text { in g (in } \\
\text { mmol) }\end{array}$ & $\begin{array}{l}\text { Anisole } \\
\text { in } \mathrm{mL}\end{array}$ & $X_{P C}{ }^{a)}$ \\
\hline 1 & PS-PC-PS & 7400 & 10000 & 5600 & 7700 & 1.00 & $\begin{array}{l}0.15 \\
(2.3)\end{array}$ & $\begin{array}{l}0.48 \\
(2.8)\end{array}$ & 5 & 0.81 \\
\hline 2 & PS-PC-PS & 9400 & 11700 & 7400 & 10100 & 1.00 & $\begin{array}{l}0.11 \\
(1.8)\end{array}$ & $\begin{array}{l}0.37 \\
(2.1)\end{array}$ & 5 & 0.37 \\
\hline 3 & $\mathrm{HO}-(\mathrm{PC})-\mathrm{OH}$ & 4800 & 6000 & 3700 & 4200 & 0.75 & $\begin{array}{l}0.11 \\
(1.8)\end{array}$ & $\begin{array}{l}0.36 \\
(2.1)\end{array}$ & 4 & 1.00 \\
\hline
\end{tabular}

Tab. 3. Results of the treatment of PPO-b-PS, PS- $b-P P O-b-P S$, and of hydroxytelechelic PPO under ATRC conditions (reactions carried out in toluene at $110^{\circ} \mathrm{C}$, GPC analyses performed in THF as the eluting solvent)

\begin{tabular}{|c|c|c|c|c|c|c|c|c|c|c|c|}
\hline No. & $\begin{array}{c}\text { Reactant } \\
\text { type }\end{array}$ & $\begin{array}{c}M_{\mathrm{w}, \mathrm{GPC}} \\
\text { reactant }\end{array}$ & $\begin{array}{l}M_{\mathrm{w}, \mathrm{GPC}} \\
\text { product }\end{array}$ & $\begin{array}{l}\text { Reactant } \\
\text { in } \mathrm{g}\end{array}$ & $\begin{array}{c}\mathrm{Cu}(0) \\
\text { in g (in } \\
\mathrm{mmol})\end{array}$ & $\begin{array}{c}\mathrm{CuBr} \\
\text { in } \mathrm{g} \text { (in } \\
\mathrm{mmol})\end{array}$ & $\begin{array}{c}\text { PMDETA } \\
\text { in } \mathrm{g} \text { (in } \\
\mathrm{mmol} \text { ) }\end{array}$ & $\begin{array}{l}\text { Toluene } \\
\text { in } \mathrm{mL}\end{array}$ & $\begin{array}{c}t \\
\text { in } \\
\mathrm{h}\end{array}$ & $\begin{array}{l}X_{\mathrm{PPO}}{ }^{\mathrm{a}} \\
\text { reactant } \\
\text { (product) }\end{array}$ & $q^{\text {b) }}$ \\
\hline 1 & $k$ & 16200 & 26100 & 0 & $\begin{array}{l}0.04 \\
(0.6)\end{array}$ & -- & & 2 & 18 & $\begin{array}{c}0.48 \\
(0.52)\end{array}$ & 4 \\
\hline $2 \mathrm{~A}$ & lock & 45000 & 123 & 0 & (2.1) & -- & (2.5) & 4 & 24 & $\begin{array}{c}0.10 \\
(0.11)\end{array}$ & 0.22 \\
\hline $2 \mathrm{~B}$ & trib & 45000 & 107900 & 1.00 & $\begin{array}{l}0.13 \\
(2.1)\end{array}$ & $\begin{array}{l}0.06 \\
(0.4)\end{array}$ & $(2.5)$ & 4 & 24 & $\begin{array}{c}0.10 \\
(0.10)\end{array}$ & 0.20 \\
\hline $3 A$ & triblock & 32400 & 85400 & 1.01 & (2.0) & -- & & 4 & 24 & $\begin{array}{c}0.13 \\
(0.16)\end{array}$ & 21 \\
\hline $3 B$ & lock & 32400 & 134600 & 1. & $\begin{array}{l}0.13 \\
(2.0)\end{array}$ & $\begin{array}{l}0.06 \\
(0.4)\end{array}$ & $\begin{array}{l}0.43 \\
(2.5)\end{array}$ & 4 & 24 & $\begin{array}{c}0.13 \\
(0.14)\end{array}$ & 0.30 \\
\hline $4 \mathrm{~A}$ & triblock & 137700 & 206800 & 1.01 & $\begin{array}{l}0.06 \\
(1.0)\end{array}$ & -- & $\begin{array}{l}0.20 \\
(1.2)\end{array}$ & 4 & 24 & $\begin{array}{c}0.21 \\
(0.21)\end{array}$ & 0.00 \\
\hline $4 \mathrm{~B}$ & triblock & 137700 & 294600 & 1.00 & $\begin{array}{l}\text { b) } \\
\text { b) }\end{array}$ & $\begin{array}{l}0.03 \\
(0.2)\end{array}$ & $\begin{array}{l}0.20 \\
(1.2)\end{array}$ & 4 & 24 & $\begin{array}{c}0.21 \\
(0.21)\end{array}$ & 0.1 \\
\hline $5 A$ & lock & 40900 & 349000 & 1.00 & 0) & -- & $\begin{array}{l}0.22 \\
(1.3)\end{array}$ & 4 & 25 & $\begin{array}{c}0.39 \\
(0.39)\end{array}$ & 0. \\
\hline $5 B$ & triblock & 40900 & $\underset{c)}{266800}$ & 0.50 & $\begin{array}{l}0.03 \\
(0.5)\end{array}$ & $\begin{array}{l}0.01 \\
(0.1)\end{array}$ & $\begin{array}{l}0.10 \\
(0.6)\end{array}$ & 2 & 24 & $\begin{array}{c}0.39 \\
(0.38)\end{array}$ & 0.31 \\
\hline 6 & triblock $^{\mathrm{d})}$ & 18100 & 199500 & 0.30 & $\begin{array}{l}0.03 \\
(0.4)\end{array}$ & $\begin{array}{l}0.01 \\
(0.1)\end{array}$ & $\begin{array}{c}0.05^{\mathrm{e})} \\
(0.2)\end{array}$ & 2 & 24 & $\begin{array}{c}0.73 \\
(0.76)\end{array}$ & 0.57 \\
\hline $7^{f)}$ & $\begin{array}{c}\text { (PPO)- } \\
\mathrm{OH}\end{array}$ & 37100 & 35700 & 1.00 & (2.3) & -- & $\begin{array}{l}0.48 \\
(2.8)\end{array}$ & 5 & 22 & $\begin{array}{c}1.00 \\
(1.00)\end{array}$ & 0.13 \\
\hline \multicolumn{12}{|c|}{ 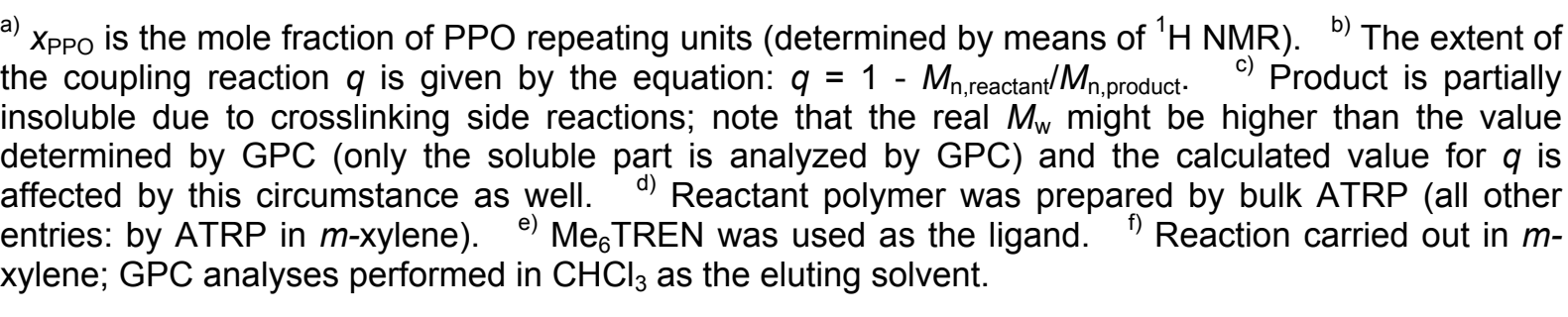 } \\
\hline
\end{tabular}


Acknowledgement: Financial support by the Center of Advanced European Studies and Research (caesar) and by the Fonds der Chemischen Industrie is gratefully acknowledged.

[1] Yoshikawa, C.; Goto, A.; Fukuda, T.; e-Polymers 2002, no. 013.

[2] Yurteri, S.; Cianga, I.; Yagci, Y.; Macromol. Chem. Phys. 2003, 204, 1771.

[3] Otazaghine, B.; David, G.; Boutevin, B.; Robin, J. J.; Matyjaszewski, K.; Macromol. Chem. Phys. 2004, 205, 154.

[4] Sarbu, T.; Lin, K. Y.; Ell, J.; Siegwart, D. J.; Spanswick, J.; Matyjaszewski, K.; Macromolecules 2004, 37, 3120.

[5] Otazaghine, B.; Boutevin, B.; Macromol. Chem. Phys. 2004, 205, 2002.

[6] Sarbu, T.; Lin, K. Y.; Spanswick, J.; Gil, R. R.; Siegwart, D. J.; Matyjaszewski, K.; Macromolecules 2004, 37, 9694.

[7] Mennicken, M.; Nagelsdiek, R.; Keul, H.; Höcker, H.; Macromol. Chem. Phys. 2004, 205, 143.

[8] Nagelsdiek, R.; Keul, H.; Höcker, H.; submitted to Polym. Int.

[9] Pilgram, P.; Ph.D. Thesis, RWTH Aachen, Germany 2002.

[10] Neumann, A.; Keul, H.; Höcker, H.; Macromol. Chem. Phys. 2000, 201, 980. 